\title{
CRIMINALIDADE NA ERA DA INFORMAÇÃO: DEFINIÇÕES SOBRE CRIMINALIDADE COMPLEXA
}

\section{CRIMINALITY IN THE INFORMATION AGE: DEFINITIONS ON COMPLEX CRIMINALITY}

\author{
${ }^{1}$ Kerolinne Barboza da Silva \\ ${ }^{2}$ Handerson Gleber de Lima Cavalcanti
}

\section{RESUMO}

$\mathrm{Na}$ era da informação, cujos dados podem viajar o mundo inteiro em frações de segundos, os conceitos de fronteiras, jurisdição, tempo e espaço sofrem uma forte interferência. Sem limites nem barreiras, o mundo digital informatizado abre também um leque de oportunidades para práticas ilícitas. Os infratores de hoje têm ao seu dispor tecnologia suficiente para potencializar seus atos, fracionar seus passos e ocultar sua identidade, ocasionando o chamado fenômeno da criminalidade complexa, que em razão de suas características absorvidas pelo mundo moderno, apresenta uma séria de problemáticas que se alastram por todo mundo e ocasionam sérios danos à sociedade global.

Palavras-chave: Criminalidade complexa. Sociedade informacional. Tecnologia

\begin{abstract}
In the age of information, which data can travel the world in fractions of seconds, the concepts of border, jurisdiction, time and space suffer severe interference. Without limits or barriers, computerized digital world also opens up a range of opportunities for criminal behavior. Today the tecnologies offer to offenders sufficient technology to Enhance Their actions, fractionate Their steps and hiding Their identity, Causing the so-called phenomenon of complex crime, which due to its characteristics absorbed by the modern world, presents a serious problem that spread around the world and cause serious damage to the global society.
\end{abstract}

Keywords: Complex crime. Information society. Technology

\footnotetext{
${ }^{1}$ Bacharel em Ciências Jurídicas pela Universidade Federal da Paraíba - UFPB, João Pessoa, (Brasil). Mestranda em Ciências Jurídicas, Área de Concentração Direito Econômico, pela Universidade Federal da Paraíba. Advogada; E-mail: kerolinneb@gmail.com

2 Bacharel em Ciências Jurídicas pela Universidade Federal da Paraíba - UFPB. João Pessoa, (Brasil). Servidor Público Estadual. Especialista em Ciências Criminais pelo Centro Universitário de João Pessoa (Unipê). E-mail: handerson.gleber@gmail.com
} 


\section{INTRODUÇÃO}

Com o surgimento do transistor, da cibernética, da internet e, principalmente, do bit, o mundo antropocêntrico deu lugar ao mundo bitcêntrico no qual o espaço real cede lugar ao Ciberespaço, onde os átomos são os bits. O ciberespaço representa uma nova realidade, um universo sem limites orgânicos e sem fronteiras espaciais ou temporais.

Nasce a era da informação na qual a difusão de informações que demoravam dias para alcançar locais além da comunidade local, passaram a percorrer o globo em frações de segundos e com a mesma velocidade com que surge, desaparecem. Vivemos num momento em que pequenos problemas locais, antes irrelevantes, passaram a ter o condão de, em poucos segundos, alçarem a esfera global e trazerem consigo consequências imensuráveis.

É nesse contexto que se fala em criminalidade complexa, um fenômeno inerente ao mundo contemporâneo, em meio ao universo virtual e rompimento de paradigmas de tempo e espaço. Os avanços tecnológicos, ao mesmo tempo que aprimoram a difusão e compartilhamento da informação, aproximando e facilitando as demandas diárias, trouxe consigo também um ambiente propício à prática de ilícitos, potencializando as condutas anteriormente praticadas, dando mais complexidade à sua execução e potencializando os possíveis danos ocasionados e consequentemente, dificultando a sua elucidação, prevenção e repressão.

\section{A VIDA E O CAOS NA ERA INFORMAÇÃO}

Em 1948 os Laboratórios telefônicos da Bell anunciaram a invenção de um pequeno semicondutor eletrônico chamado de transistor. O transistor deu início a uma revolução na eletrônica, colocando a tecnologia no rumo da miniaturização e da onipresença. Entretanto, neste mesmo ano, sem qualquer holofote ou comunicado à imprensa, numa monografia publicada na Revista Técnica dos Sistemas Bell sob o título "Uma teoria matemática da comunicação", surgia também uma outra invenção em torno do qual o mundo inteiro passou a girar: o bit - binary digit, a menor de medida de informação que pode ser armazenada ou transmitida. (GLEICK, 2013) Um bit pode assumir somente 2 valores: 0 ou 1, corte ou passagem de energia respectivamente: 
Shannon afirmou: "As unidades resultantes podem ser chamadas de dígitos binários, ou, numa versão mais curta, de bits". [...] Por ser a menor quantidade possível de informação, um bit representa a quantidade de incerteza que existe no arremesso de uma moeda. [...] Se os dois lados de uma moeda seriam uma maneira de representar um bit, Shannon ofereceu também um exemplo mais prático de equipamento: Um dispositivo com duas posições estáveis, como um relé ou um circuito flip-flop, pode armazenar um bit de informação. $\mathrm{N}$ dispositivos desse tipo podem armazenar $\mathrm{N}$ bits, já que o número total de estados possíveis é $2 \mathrm{~N}$ e $\log 22 \mathrm{~N}=\mathrm{N}$.[...]Shannon tinha visto dispositivos - conjuntos de relés, por exemplo - que eram capazes de armazenar centenas ou até milhares de bits. Isso parecia uma quantidade impressionante. (GLEICK, 2013)

Com o nascimento do bit e do transistor estava iniciada a "Era da Informação". Nessa nova era, os bits, megabits, gigabits tornaram-se o principal combustível do mundo e da vida. A eletricidade, por via da luz (em fibras ópticas, ou em leitores e gravadores de discos ópticos por exemplo), a rede wireless, através de ondas eletromagnéticas, e até áreas da ciência como a biologia, ao examinar o armazenamento e a transferência da informação pelos genomas, são meios que utilizam a medida de informação.

A Sobrevivência humana, perpassou a necessidade material de água e comida, sede e fome (GLOBO NEWS, ${ }^{3}$ e conectou-se a uma nova solução. A Cibernética ${ }^{4}$ tomou conta da realidade. As palavras estão em toda parte e em lugar nenhum. O universo, passou então a se assemelhar a um computador que computa o seu próprio destino:

Aquilo que jaz no coração de cada ser vivo não é uma chama, nem um hálito quente nem uma faísca de vida. É a informação, palavras, instruções. Se quiser uma metáfora, não pense em fogos, faíscas ou hálitos. Pense em vez disso num bilhão de caracteres distintos gravados em tabuletas de cristal. Richard Dawkins apud (GLEICK, 2013)

A difusão de notícias que demoravam dias para alcançar locais além da comunidade local e se tornavam assunto eternos, hoje, percorre o mundo em frações de segundos e com a mesma velocidade com que surge, desaparecem. Se antes, para compreendermos o presente, debatíamos sobre o passado, registrado em livros e jornais cuja produção se deu muito tempo após a consumação do fato histórico, atualmente, vivemos e debatemos o presente ininterruptamente, retratado ao vivo, a cores e em alta definição.

3 Referência à vinheta: "Se não for fresca não serve/ Sem conteúdo não sustenta/ Muito rebuscada complica/ Se não cheirar bem é melhor investigar/Se não acrescenta você deixa de lado/ Sem bom senso não é levada a sério/ E quando é feita por quem entende você vê logo a diferença/ Informação que é nem comida: alimenta. (GLOBO NEWS, Acesso em: 25/03/2014)

$4 \mathrm{Ci} \cdot$ ber·né·ti·ca (inglês cybernetics, do grego kubernetikê, arte do piloto, arte de governar) Ciência que estuda os mecanismos de comunicação e de controle nas máquinas e nos seres vivos. ( Dicionário Priberam da Língua Portuguesa, s.d.) 
Pequenos problemas locais, antes irrelevantes, passaram a ter o condão de, em poucos segundos, alçarem a esfera global e destruírem por completo qualquer espécie de reputação ou política, tornando os gestores públicos permanentemente reféns do chamado "efeito borboleta $^{5}$," ressaltado por Turing:

O sistema do "universo como um todo" é tal que erros bastante pequenos nas condições iniciais podem trazer efeitos irresistíveis num momento posterior. $\mathrm{O}$ deslocamento de um único elétron em um bilionésimo de centímetro num dado momento pode resultar na diferença entre um homem ser morto por uma avalanche um ano mais tarde, ou escapar dela (TURING, 1950).

As identidades sociais, antes associadas a grupos que ocupavam um espaço físico e nele construíam seus valores, suas memórias e suas tradições, tem-se transformado junto com a ideia de fronteira física, dando origem a novas formas de agrupamento humano e assimilação social (DE CARVALHO, 2006). A cada dia que passa, as novas tecnologias modificam a dinâmica contemporânea e os conceitos de território, tempo e espaço sofrem constantes alterações, como afirma Oliven:

\footnotetext{
Embora as noções de território e de fronteira tenham existido em diferentes momentos históricos, seus significados variam no tempo e no espaço. (...) O conceito de Estadonação está sendo afetado pela compressão do tempo e do espaço, na medida em que a velocidade da informação e dos deslocamentos se intensifica e faz com que as mudanças se acelerem cada vez mais. (OLIVEN, 2006)
}

Assim, com inúmeras informações trafegando o mundo na velocidade da luz a cada dia surgem novos neologismos em cadência exponencial: Wikipedia, Google ${ }^{6}$, Troll $^{7}$, SPAM $^{8}$, fibra ótica, wifi, 3g, internet, e-gov, crowdsourcing, hacktivismo, e uma série de outras inovações que tem construído uma realidade:

"A Wiki não é papel" era o lema não oficial. De maneira autorreferencial, a expressão
tem seu próprio verbete enciclopédico (ver também "Wiki ist kein Papier" e
"Wikipédia n'est pas sur papier"). Significa que não existe limite físico nem
econômico para o número ou a extensão dos artigos. Os bits são gratuitos. "Todo tipo
de metáfora envolvendo o papel ou o espaço está morta", nas palavras de Wales.
(GLEICK, 2013)

Entretanto, embora o desenvolvimento tecnológico tenha promovido diversas mudanças no meio social, possibilitado a resolução de uma miríade de problemas humanos até

5 " (...) the flap of a butterfly's wings in Brazil today may make the difference between calm weather and a tornado in Texas next month(...)”. (LORENZ, 1994.)

6 GOOGLE - vb- to search for (something on the internet) using a search engine (COLLINS, 20/05/14)

7 SPAM - vb - to send unsolicited electronic mail or text messages simultaneously to a number of e-mail addresses or mobile phones (COLLINS, 20/05/14)

8 TROLL - vb - slang ( intr ) computing to post deliberately inflammatory articles on an internet discussion board (COLLINS, 20/05/14) 
então insolúveis, também fez surgir a criminalidade complexa através de estruturas (associações, grupos ou organizações) dotadas de elevados níveis de influência, capital, conhecimento ou belicosidade, finalidades ilícitas e potenciais destrutivos utópicos, no quais um único "clique" tem a capacidade de aniquilar toda uma cidade, um continente ou mesmo o planeta:

\begin{abstract}
Para além da microcriminalidade, que se revela em delitos ordinários e de pequena escala praticados isoladamente por indivíduos ou em mero concurso de agentes, a macrocriminalidade ou chamada criminalidade avançada difere da primeira em razão das proporções, intensidade e natureza. Muitas vezes, a macrocriminalidade apresenta-se sobre formas empresariais, como produto de organização e cooperação de criminosos que reproduzem, no campo do ilícito, métodos de empresas, com grande potencial de lesão à sociedade e ao Estado. (SILVA, 2014)
\end{abstract}

Ao passo que a capacidade destrutiva da criminalidade complexa cresce, ocorre a falência sistêmica dos organismos policiais tradicionais que se veem incapazes de prevenir, investigar e reprimir, ${ }^{9}$ o que contribuí para disseminação da violência urbana e da sensação de insegurança crescente, que, com a toda ultra visibilidade, vem sendo transformadas em espetáculos pela indústria midiática, e aproveitadas pela "criminologia midiática" para justificação de políticas criminais intolerantes e atentatórias aos direitos fundamentais. (BOLDT, 2013). A violência, deixou de ser um drama urbano e passou a ser o show da vez, transmitida todos os dias em diversos horários tal qual preconizava Ray Bradbury em sua distopia Farenheit 451.

Nesse sentido, o caos da nova sociedade se refletiu no surgimento da criminalidade complexa:

\begin{abstract}
“[...] estamos diante de uma transformação dos paradigmas criminológicos oriundos do positivismo. Isso quer dizer que os fenômenos criminais não podem mais ser enfocados exclusivamente do ponto de vista individual e local, pois tornaram-se fenômenos globais, sistêmicos e organizados em redes criminosas e legais que funcionam em permanente interação." (ANSELMO, 2012)
\end{abstract}

Desta feita, sentimos os impactos dessas transformações não apenas de maneira positiva, posto que essas mudanças trazem consigo uma série de fenômenos criminais instrumentalizados pela nova era da tecnologia e informação.

9 Em meados de 2012 foi divulgado o Relatório Nacional da Execução da Meta 2 da Estratégia Nacional de Justiça e Segurança Pública - ENASP. De acordo com o documento, o índice de elucidação dos crimes de homicídio é baixíssimo no Brasil, estima-se, em pesquisas realizadas, inclusive a realizada pela Associação Brasileira de Criminalística, 2011, que varie entre 5\% e $8 \%$. (VOITCH, s.d.) 


\section{CRIMINALIDADE COMPLEXA}

As ferramentas participativas da modernização econômica e sociopolítica, tornaram o indivíduo a referência fundamental e a unidade de cálculo econômico e político, paradoxalmente, o mesmo indivíduo é desinteressado em relação aos seus próprios interesses, sempre que indivisivelmente compartilhados, tendendo a evadir-se de participar nos encargos necessários a consecução das utilidades comunitárias, causando assim o declínio da esfera pública:

\footnotetext{
Há claramente, nas sociedades mais modernas e complexas, uma cultura de evasão e de absenteísmo políticos, comum as classes altas, as elites e as populações mergulhadas na pobreza sevara. Os ricos cada vez mais convertem as suas residências e os seus bairros em fortalezas. Nos bairros pobres, dominados pela deterioração e pela insegurança, os habitantes recolhem-se cedo, intimidados pelo narcotráfico e pela violência. (TAVARES, 2006)
}

A erosão nas noções republicanas de obrigação política e de responsabilidade pública, aliada aos avanços tecnológicos, culminaram na promoção de uma nova criminalidade com facetas inovadoras: a Criminalidade Complexa. (TAVARES, 2006)

Considera-se criminalidade complexa, ou crimes de natureza complexa, aquele cuja operacionalização demanda altos níveis de conhecimento, influência, capital ou belicosidade e o resultado apresenta um extenso potencial lesivo para a sociedade. Os avanços tecnológicos e a nova era da informação acabaram por também reforçar a prática de condutas ilícitas e proporcionaram um meio proeminente de articulação de novas modalidades criminosas.

Portanto, neste conceito de criminalidade complexa, encontramos uma série de práticas ilícitas dentre as quais cyber crimes, crime organizado e terrorismo em suas diversas facetas como o terrorismo nuclear e bioterrorismo.

Ao falar em cyber crimes, compreende-se os crimes virtuais em geral praticados pela internet. Sua existência é puramente virtual, gerando poucos reflexos no mundo físico. Como sua execução ocorre no ciberespaço, não há como definir seguramente um "local do crime" nem mesmo um "tempo do crime". As investigações destes tipos de crimes, requerem o envolvimento de diferentes estados e países que muitas vezes são separados por milhas de distâncias, sistemas jurídicos distintos e culturas antagônicas.

No que tange ao Crime organizado, temos a construção de verdadeiras estruturas empresariais para a prática de ilicitudes. O crime organizado veste diferentes máscaras e pratica uma enorme variedade de ilicitudes, das quais, como as que exigem maior complexidade e organização, o tráfico internacional e o tráfico de influência. 
Tráfico internacional, trata-se de crimes que envolvem a transferência ilícita entre Estados diferentes, de objetos ou seres humanos. No caso do tráfico de objetos podemos encontrar os tráficos de armas, drogas, plantas, animais, bebidas e tabaco. Já no que diz respeito ao tráfico de humanos, visualizamos os tráficos de mulheres, crianças, órgãos humanos e outros. Por sua vez, tráfico de influência e poder compreende crimes que visam o controle ou o domínio sobre o governo ou o poder público, de maneira não violenta, através do uso de influência política ou poder econômico, afetando diretamente o Estado Democrático de Direito. No Brasil, o recente caso do "mensalão" e "petrólão", demonstram a lesividade e a complexidade de tais crimes. Tal qual os cybers crimes, as investigações relacionadas as organizações criminosas requerem a cooperação e o envolvimento de diversas jurisdições, sobre tudo em razão do poder de influência que seus autores.

Por fim, temos o terrorismo, terrorismo nuclear e bioterrorismo, que são enquadrados como disseminação do terror e do caos com fins ideológicos, através de ações violentas, ou ameaça de ação, contra grupos indefesos. Devido ao seu imenso poder de destruição, a sua prevenção exige esforços incomuns, para se evitar resultados calamitosos.

Passemos a uma breve análise dos impactos dessas condutas criminosas propiciadas pelo universo tecnológico contemporâneo, que adquiriram características peculiares e de extrema complexidade e consequente dificuldade de se prevenir, elucidar e reprimir.

\subsection{Cibercrimes}

No site oficial da empresa de segurança digital Norton Symantec, conhecida pelos seus softwares de antivírus, temos a seguinte definição para o cibercrime:

Tal como a criminalidade tradicional, a cibercriminalidade pode assumir muitas formas e pode ocorrer quase a qualquer hora ou lugar. Os criminosos cibernéticos usam métodos diferentes segundo suas habilidades e seus objetivos. Esse fato não deveria ser surpreendente, afinal, o crime cibernético é nada mais que um "crime" com um ingrediente "informático" ou "cibernético". (NORTON SYMANTEC, 2016)

O Conselho Europeu através a Convenção sobre o Cibercrime, também conhecida como Convenção de Budapeste, usa o termo "cibercrime" para definir delitos como de violações de direito autoral, fraudes relacionadas a computador, pornografia infantil e violações de segurança de redes. A Convenção, aprovada em 2001, é considerada uma referência legislativa mundial a respeito do assunto.

No Brasil temos a lei 12.737/12, que dispõe sobre a tipificação criminal de delitos informáticos, que traz delitos como: invasão de dispositivo informático, interrupção ou 
perturbação de serviço telegráfico, telefônico, informático, telemático ou de informação de utilidade pública, e Falsificação de cartão

Invasão de dispositivo informático

Art. 154-A. Invadir dispositivo informático alheio, conectado ou não à rede de computadores, mediante violação indevida de mecanismo de segurança e com o fim de obter, adulterar ou destruir dados ou informações sem autorização expressa ou tácita do titular do dispositivo ou instalar vulnerabilidades para obter vantagem ilícita: $[\ldots]$

"Interrupção ou perturbação de serviço telegráfico, telefônico, informático, telemático ou de informação de utilidade pública

Art. 266.

$\S 1^{\circ}$ Incorre na mesma pena quem interrompe serviço telemático ou de informação de utilidade pública, ou impede ou dificulta-lhe o restabelecimento.

§ 20 Aplicam-se as penas em dobro se o crime é cometido por ocasião de calamidade pública." (NR)

Falsificação de documento particular

Art. 298.

Falsificação de cartão

Parágrafo único. Para fins do disposto no caput, equipara-se a documento particular o cartão de crédito ou débito. (BRASIL, 2012)

De acordo com a ONU, o cibercrime é um dos crimes organizados transnacionais que mais crescem no mundo e já afeta milhões de pessoas em todo o planeta. Ele se manifesta em diferentes formas, como delitos relacionados à identidade, violações de direitos autorais, pornografia infantil e abusos. É uma das maiores ameaças para os 2 bilhões de usuários da internet que, conscientes ou não, armazenam informação online. Com o aumento da facilidade de cometer este crime, agentes da lei encontram cada vez mais dificuldades para conter sua propagação frente aos desafios impostos pelos avanços tecnológicos. Países em desenvolvimento, principalmente, não têm a capacidade para combater os ataques virtuais e por isso contam com um índice mais alto de vítimas. Neste contexto, a necessidade para proteger os cidadãos em todo nunca foi tão importante. ${ }^{10}$ (ONU, 2016)

\footnotetext{
${ }^{10}$ Cybercrime is an emerging form of transnational crime, and one of the fastest growing. As the Internet has become an almost essential part of our lives, providing information and communication all over the world, so criminals have taken advantage. With some two billion users worldwide, cyberspace is the ideal place for criminals because they can remain anonymous and gain access to all forms of personal information we knowingly, or unwittingly, store online. Threats to Internet safety have spiked dramatically in recent years, and cybercrime now affects more than 431 million adult victims globally. (ONU, 2016)
} 
Podemos, portanto, adotar o conceito de Cibercrimes como sendo crimes que envolvem um conjunto de práticas na rede de computadores, tais quais invasões de sistema, disseminação de vírus, roubo de dados pessoais, falsidade ideológica, acesso a informações confidenciais e tantos outros, bem como crimes convencionais que se utilizam de dispositivos eletrônicos ou meios digitais como instrumento para sua prática.

O cibercrime, é uma área em rápida expansão, pois o seu número de vítimas já ultrapassa significativamente os crimes tradicionais. De acordo com a Safernet Brasil, uma organização não governamental com parceria com o governo brasileiro, em 2015, através de denúncias registradas pela população em hotlines brasileiros que integram a Central Nacional de Denúncias de Crimes Cibernéticos, foram recebidas e processadas 139.643 denúncias anônimas envolvendo 43.070 páginas (URLs) distintas (das quais 8.300 foram removidas), escritas em 8 idiomas e hospedadas em 6.755 hosts diferentes, conectados à internet através de 4.821 números IPs distintos, atribuídos para 63 países em 5 continentes. As denúncias envolvem ilicitudes praticadas pelo meio virtual como: intolerância religiosa; tráfico de pessoas; neo nazismo; racismo; pornografia infantil; maus tratos contra animais; xenofobia; apologia e incitação a crimes contra a vida e homofobia (SAFERNET, 2016)

Cada vez mais, criminosos tem explorado a velocidade, a conveniência e o anonimato da rede mundial para praticarem uma vastidão de atividades criminosas que desconhecem fronteiras e limites físicos, e representam novas ameaças a economia global. (INTERPOL, 2016)

Taxas de vitimização por fraude de cartão de crédito online, roubo de identidade, vítima de uma tentativa de phishing, e o acesso não autorizado a uma conta de e-mail, variam entre 1 e 17 por cento da população on-line para 21 países em todo o mundo, em comparação com o roubo típico, as taxas de roubo de carro chegam a menos de 5 por cento para esses mesmos países. Taxas de vítimas de cibercrime são mais elevados em países com baixos níveis de desenvolvimento, destacando a necessidade de reforçar os esforços de prevenção nesses países.

11. (UNODC U. , 2013)

O cibercrime tem a peculiaridade de que nem todo ele será praticado exclusivamente por uma estrutura criminal complexa (organizações criminosas e outros). Um simples jovem hacker, por exemplo, do computador de sua casa no Brasil, poderá, através de servidores norte americanos, conectar-se a servidores proxy russos, para invadir sites de bancos suíços, roubar

11 "Victimization rates for online credit card fraud, identity theft, responding to a phishing attempt, and experiencing unauthorized access to an email account, vary between 1 and 17 per cent of the online population for 21 countries across the world, compared with typical burglary, robbery and car theft rates of under 5 per cent for these same countries. Cybercrime victimization rates are higher in countries with lower levels of development, highlighting a need to strengthen prevention efforts in these countries." 
milhões em valores monetários de diversas contas bancárias, deposita-los em uma conta clandestina em um banco na Iugoslávia, para em seguida, converte-los em bitcoins em servidores na Alemanha e utilizar as moedas virtuais para comprar produtos exportados da China, através de um site argentino.

O ilícito exemplificado, foi praticado por uma única pessoa isoladamente e sem a necessidade de grandes investimentos, salvo o próprio estudo em informática do autor, porém, sua investigação demandará esforços internacionais incomuns.

Todavia, na maior parte, os recursos exigidos para estas práticas delitivas, tendem a se concentrarem na mão de verdadeiras empresas criminosas, que detém poderes para alavancar sua produção. Em contrapartida, o Estado responde de forma ainda ineficiente e despreparada, de maneira que carece da cooperação entre os demais entes estatais, posto que o crime acaba sendo fracionado, tendo sido praticado sob diversas jurisdições através do espaço virtual, evidenciando a dificuldade, perante esta era tecnológica que rompe barreiras e fronteiras.

\subsection{Organizações Criminosas}

No Brasil, a Convenção das Nações Unidas contra o Crime Organizado Transnacional de novembro do ano de 2000 (Convenção de Palermo), promulgada quatro anos depois, com a edição do Decreto 5.015, de março de 2004, define em seu Artigo $2^{\circ}$, grupo criminoso organizado como:

Artigo $2^{\circ}$ - [...] a) "Grupo criminoso organizado" - grupo estruturado de três ou mais pessoas, existente há algum tempo e atuando concentradamente com o propósito de cometer uma ou mais infrações graves ou enunciadas na presente Convenção, com a intenção de obter, direta ou indiretamente, um benefício econômico ou outro benefício material; [...] (BRASIL, Decreto ${ }^{\circ}$ 5.015, 2014)

Todavia, após diversas críticas dos doutrinadores brasileiros, a definição da Convenção de Palermo, considerada ampla o suficiente para violar o princípio da legalidade (GOMES, 2009). Em 24 de julho de 2012, o Congresso Nacional, aprovou a Lei 12.694, com nova definição para efeito de processo e julgamento, e em seguida, em 2 de agosto de 2013, aprovou a Lei $n^{\circ} 12.850$, definindo organização criminosa em matéria penal:

$\operatorname{Art} 1^{\circ}[\ldots] \S 1^{\circ}$ Considera-se organização criminosa a associação de 4 (quatro) ou mais pessoas estruturalmente ordenada e caracterizada pela divisão de tarefas, ainda que informalmente, com objetivo de obter, direta ou indiretamente, vantagem de qualquer natureza, mediante a prática de infrações penais cujas penas máximas sejam superiores a 4 (quatro) anos, ou que sejam de caráter transnacional. (BRASIL, Lei $\mathrm{n}^{\circ}$ $12.850,2013)$ 
Estima-se que pelo mundo, as organizações criminosas lucrem aproximadamente 870 bilhões de dólares ao ano, estas imensas receitas equivalem a 1,5\% do PIB mundial ou a 7\% das exportações mundiais de mercadorias. (ONU, Naçoes Unidas no Brasil, 2013)

No Brasil, o Primeiro Comando da Capital (PCC) é apontado como a maior organização criminosa do país, em número de filiados e simpatizantes. Comanda grande parte do crime organizado no Estado de São Paulo, especialmente o tráfico de drogas na grande São Paulo e na baixada Santista. A facção é dirigida exclusivamente de dentro dos presídios, totalizando cerca de 6 mil integrantes. (ÉPOCA, 2016)

Neste sentido, Antônio Carlos Iranlei, aponta:

[...] a organização criminosa transnacional tende a monopolizar o mercado financeiro mundial, alargando a possibilidade de falência de instituições bancárias, empresas lícitas, chegando ao ponto de criar enormes obstáculos para os Estados na fixação das taxas de juros e até mesmo, de sua política econômica. Assim, os criminosos manipulam, com êxito, quase todos os sistemas financeiros do mundo contemporâneo. (IRANLEI, 2014)

Callegari apud Iranlei, faz uma observação importante acerca do crime organizado:

[...]as consequências em termos de disfuncionalidade que o mecanismo do crime organizado produz no sistema de vida social e marcadamente no mercado. O peso específico alcançado pelo crime organizado termina, com efeito, em falsificar a liberdade do sistema econômico, alterando a igualdade e condições e as mesmas regras do jogo do mercado, de modo que os efeitos negativos da ingerência do tipo mafiosas no circuito econômico-financeiro se propagam em grande escala, numa sorte de diabólica reação em cadeia. (IRANLEI, 2014)

Nesse sentido, compreende-se que o crime organizado abastece a criminalidade local das cidades, aumentando o nível geral de insegurança e afronta os direitos humanos fundamentais, particularmente quando são levados em consideração atividades de sequestros e extorsões, neste prumo, ressalta documento da UNODC:

Enquanto o crime organizado transnacional é uma ameaça global, os seus efeitos são sentidos localmente. Quando o crime organizado toma a raiz pode desestabilizar países e regiões inteiras, comprometendo assim a assistência ao desenvolvimento nessas áreas. Grupos do crime organizado também pode trabalhar com criminosos locais, levando a um aumento da corrupção, extorsão, extorsão e violência, bem como uma série de outros crimes mais sofisticados a nível local. Gangues violentas também podem transformar cidades do interior em áreas perigosas e colocar a vida dos cidadãos em risco. Todos os anos, inúmeras vidas são perdidas como resultado do crime organizado. Problemas relacionados com a droga de saúde e violência, mortes por arma de fogo e os métodos inescrupulosos e os motivos dos traficantes de seres humanos e contrabandistas migrantes são todos parte deste. A cada ano, milhões de vítimas são afetados como resultado das atividades dos grupos do crime organizado. (UNODC, 2016) 
De acordo com o então subprocurador geral da república, Carlos Eduardo de Oliveira Vasconcelos, os atos deflagrados por facções criminosas constituem um fenômeno típico de Estados fracos, incapazes de afirmar sua supremacia em certos espaços territoriais, até mesmo em presídios. (VASCONCELOS, 2014)

Diante das peculiaridades, a ONU afirma que o crime organizado "ameaça a paz e a segurança humana, e prejudica o desenvolvimento económico, social, cultural, política e civil das sociedades em todo o mundo”. E que, para combater a ameaça global que ele representa, é necessárias parcerias em todos os níveis: governos, empresas e sociedade civil.

Nesse sentido, compreende as Nações Unidas que os sistemas de justiça penal e os métodos de aplicação da lei convencionais muitas vezes não são páreo para as redes criminosas poderosas, acarretando a necessidade de melhores métodos de inteligência desenvolvidas através da formação de unidades mais especializadas de aplicação da lei, equipado com tecnologia suficiente para combater essa criminalidade complexa. (UNODC, 2016)

\subsection{Terrorismo e Organizações Terroristas}

Uma espécie bastante peculiar de estrutura complexa, são as organizações terroristas, que com seu alto poder de destruição, acabam por representarem uma ameaça ainda maior do que as organizações puramente criminosas.

De acordo com a Encyclopedia of Espionage, Intelligence and Security, terrorismo é a crença sistemática na eficácia política, religiosa e ideologia, do terror. Assim, organizações terroristas são grupos cuja finalidade é a disseminação de ideologias através do pânico causado por ações ou ameaças de violência contra populações indefesas. (KNIGNT, 2004)

Na legislação Brasileira, o Decreto N 5.639, De 26 De Dezembro De 2005 promulgou a Convenção Interamericana contra o Terrorismo, que tratou da necessidade de medidas para prevenção e combate, e em 2016, finalmente foi promulgado a Lei $n^{\circ} 13.260$, que conceitua terrorismo como:

Art. $2^{\circ} \mathrm{O}$ terrorismo consiste na prática por um ou mais indivíduos dos atos previstos neste artigo, por razões de xenofobia, discriminação ou preconceito de raça, cor, etnia e religião, quando cometidos com a finalidade de provocar terror social ou generalizado, expondo a perigo pessoa, patrimônio, a paz pública ou a incolumidade pública.

[...] $§ 1$ lo São atos de terrorismo:

I - usar ou ameaçar usar, transportar, guardar, portar ou trazer consigo explosivos, gases tóxicos, venenos, conteúdos biológicos, químicos, nucleares ou outros meios capazes de causar danos ou promover destruição em massa;

$[\ldots]$ 
IV - sabotar o funcionamento ou apoderar-se, com violência, grave ameaça a pessoa ou servindo-se de mecanismos cibernéticos, do controle total ou parcial, ainda que de modo temporário, de meio de comunicação ou de transporte, de portos, aeroportos, estações ferroviárias ou rodoviárias, hospitais, casas de saúde, escolas, estádios esportivos, instalações públicas ou locais onde funcionem serviços públicos essenciais, instalações de geração ou transmissão de energia, instalações militares, instalações de exploração, refino e processamento de petróleo e gás e instituições bancárias e sua rede de atendimento;

V - atentar contra a vida ou a integridade física de pessoa [...] (BRASIL, 2016)

No âmbito internacional, a Organização das Nações Unidas e países mundo, a exemplo dos Estados Unidos da América e da Inglaterra, também definiram o terrorismo em seus diplomas legais. Nos EUA, o ato é regulado pela a public law 95-511 - "Foreign Intelligence Surveillance Act Of 1978” (FISA); e pela public law 107-56 - “Uniting And Strengthening America By Providing Appropriate Tools Required To Intercept And Obstruct Terrorism Act Of 2001" (USA PATRIOT ACT) : ${ }^{12}$

Terrorismo doméstico significa atividades que:

(A) Envolver atos perigosos para a vida humana que são uma violação das leis penais de os EUA ou de qualquer estado;

(B) Que parecem estar destinados (i) intimidar ou coagir uma população civil, (ii) Para a política de um governo por intimidação ou coerção, ou (iii) Para afetar a conduta de um governo de destruição em massa, assassinato, ou seqüestro e

(C) ocorrem principalmente no âmbito da jurisdição territorial da U.S. (USA, 2001)

Enquanto que na Inglaterra a ação é prevista no Terrorism Act of 2000:

(1) Neste ato, "terrorismo" significa o uso ou ameaça de ação onde- (a) A ação enquadra subseção (2), (b) O uso ou a ameaça seja concebida para influenciar o governo ou uma organização governamental internacional ou para intimidar o público ou uma parte do público, e (c) o uso ou a ameaça é feita com o propósito de fazer avançar uma causa racial ou ideológico político, religioso.

(2) A ação inscreve-se nesta subseção se ele- (a) envolve a violência grave contra uma pessoa, (b) envolve sérios danos à propriedade, (c) põe em perigo a vida de uma pessoa, que não seja o da pessoa que comete a ação, (d ) Cria um risco grave para a saúde ou segurança do público ou uma parte do público, ou (e) foi projetado seriamente interferir ou de perturbar gravemente um sistema electrónico.

(3) O uso ou ameaça de ação abrangida subseção (2), que envolve o uso de armas de fogo ou explosivos é o terrorismo se subseção ou não (1) (b) é satisfeita. (ENGLAND, 2000)

O Conselho de Segurança da Organizações das Nações Unidas (ONU), por sua vez, adota através da Resolução 1566 de 08 de outubro de 2004, o conceito de terrorismo é:

[...] atos criminosos, incluindo contra civis, cometidos com a intenção de causar a morte ou ferimentos graves, ou tomada de reféns, com o objetivo de provocar um estado de terror no público em geral ou em um grupo de pessoas ou de pessoas

12 USA. PUBLIC LAW 107-56 - OCT. 26, 2001. Uniting And Strengthening America By Providing Appropriate Tools Required To Intercept And Obstruct Terrorism (Usa Patriot Act) Act Of 2001. CONGRESSIONAL RECORD, Vol. 147 (2001): 
particulares, intimidar uma população ou obrigar um governo ou uma organização internacional a praticar ou abster-se de praticar qualquer acto, que constituem crimes no âmbito do e como definido nas convenções e protocolos relativos ao terrorismo internacional [...]

Para o então Secretário-Geral da ONU, Ban Ki-moon (ONU, 2013), o terrorismo, em todas suas formas é uma das mais graves ameaças à paz internacional e "um dos maiores desafios relacionados à segurança de nossos tempos”, e sua atuação, "têm consequências econômicas graves e causam grandes estragos para a estabilidade e a harmonia regional dos Estados".

Atos terroristas, são extremados e possuem um grande poder de destruição, afetando a vida de um grande número de pessoas. A elucidação desses atos, normalmente não encontram dificuldade, pois seus autores em geral, são mártires que buscam exposição máxima, quando não cometem suicídios, para ampliar a difusão da sua ideologia. (LUFT, 2004)

Os ataques terroristas são atos desesperados daqueles que se sentem de outra forma impotente. O terrorismo é hipócrita, absolutista, e exclusivista. Em geral, os adeptos da política terroristas estão relutantes ou incapazes de negociar com seus inimigos percebidos, ou impedida por circunstâncias políticas, sociais ou econômicas de fazêlo. (LUFT, 2004)

Nos últimos meses temos acompanhado, infelizmente, muitos ataques terroristas pelo mundo, onde dentre os mais recentes e relevantes, destacam-se os atentados ocorridos nos Estados Unidos, onde um atirador matou 49 pessoas numa boate gay em Orlando e em junho, atiradores invadiram o aeroporto de Istambul e mataram 44 pessoas.

$\mathrm{Na}$ Europa, ataques coordenados no aeroporto e metrô de Bruxelas deixaram 32 mortos em março, enquanto na França, em 14 de julho, o motorista de um caminhão matou 84 pessoas em Nice, na França. (G1, 2016)

Desta forma, o principal problema do terrorismo para a segurança pública, não é a sua repreensão, mas sim a sua prevenção. A punição do autor do ato extremado, quando sobrevivente, é uma reparação ínfima se comparado ao dano que os atentados produzem, posto que os atos de terrorismo geram consequências devastadoras. 


\section{CONCLUSÃO}

O paradigma contemporâneo conquanto tenha construindo uma miríade de inovações também trouxe de carona um conjunto de mazelas que proporcionaram um meio proeminente para articulação de um novo gênero criminal, a criminalidade complexa, dentro da qual estão as espécies: cibercrimes, organizações criminosas e terrorismo.

Essa nova forma de ilicitude possui algumas características principais, dentre as quais:

- Sua operacionalização demanda altos níveis de conhecimento, influência, capital ou belicosidade.

- O alto potencial destrutivo chega ao ponto de em alguns casos, em especial no terrorismo, a concretização da justiça penal se tornar insignificantes diante dos danos causados a sociedade.

- A falência dos instrumentos policiais tradicionais baseados na busca da autoria e da materialidade de um fato típico pretérito ou no simples policiamento ostensivo, como o previsto no art. 144 da Constituição da República Federativa do Brasil.

Neste norte, se faz necessário que tanto o Estado quanto o direito se atualize a nova realidade da era da informação. Os mecanismos policiais precisam se atualizarem e aprenderem a trabalhar, em especial, com o maior substrato do mundo contemporâneo, a informação.

Conforme afirma a convenção de Budapeste: "uma luta efetiva contra a cibercriminalidade requer uma cooperação internacional em matéria penal acrescida, rápida e eficaz", assim como uma cooperação entre os Estados e a indústria privada. Os mecanismos policiais, portanto, precisam acima de tudo desenvolver mecanismos de cooperação público privada e, sobretudo, aprender a investir em inteligência e gestão da informação.

Compreender o paradigma em que vivemos é essencial, posto que na nova dinâmica político-econômica mundial, extremamente marcada pela competitividade, o conhecimento e sua proteção se tornaram fatores essenciais para assegurar aos Estado a sua sobrevivência.

O presente artigo teve, portanto, o fim de, suscintamente, trazer alguns conceitos da criminalidade complexa que assola o mundo contemporâneo, com intuito de subsidiar debates que possam buscar formas de aperfeiçoamento da segurança pública. 


\section{REFERÊNCIAS}

Dicionário Priberam da Língua Portuguesa. (s.d.). Acesso em <22/09/2016>, disponível em Dicionário Priberam da Língua Portuguesa: http://www.priberam.pt/dlpo/cibern\%C3\%A9tica

ANSELMO, M. A. (2012). A Ameripol e o novo paradigma da cooperção policial internacional. Segurança Pública e Cidadania.

BOLDT, R. (2013). Criminologia Midiática - Do Discurso Punitivo à Corrosão Simbólica do Garantismo. Curitiba: $1^{\circ}$ ed. Editora Jurua.

BRANDÃO, P. C. (2010). Serviços secretos e democracia no cone sul: premissas para uma convivência legítima, eficiente e profissional. Niteroi, RJ,:: Impetus.

BRASIL. (02 de Agosto de 2013). Lei no 12.850.

BRASIL. (Março de 2014). Decreto $n^{\circ} 5.015$.

BRASIL. (16 de Março de 2016). Lei no 13.260.

CAPRIGLIONE, L. (s.d.). Eles não estão nem aí| Laura Capriglione. Acesso em <24/06/2014>, disponível em Yahoo Notícias": <https://br.noticias.yahoo.com/blogs/lauracapriglione/eles-n\%C3\%A3o-est\%C3\%A3o-nem-a\%C3\%AD-001233971.html>

COLlinS, H. (20/05/14). Harper Collins. Fonte: Collins English Dictionary Complete \& Unabridged 10th Edition. : <http://dictionary.reference.com/browse/GOOGLE>

DE CARVALHO, E. M. (2006). Fronteiras no direito e os direitos sem fronteira. Em O. F. Barcellos, Fronteiras: Arte e pensamento na época do multiculturalismo. Porto Alegre: Sulina. 
ENGLAND. (20 de Julho de 2000). Terrorism Act 2000. Inglaterra.

ÉPOCA, R. (maio de 2016). Por dentro do PCC. Fonte: Revista época: http://revistaepoca.globo.com/Epoca/0,6993,EPT1199074-1659,00.html

G1. (22 de setembro de 2016). Ataques terroristas deixam centenas de mortos em 2016. Fonte: G1 Globo: http://g1.globo.com/jornal-nacional/noticia/2016/07/ataquesterroristas-deixam-centenas-de-mortos-em-2016.html

GLEICK, J. (2013). A Informação : Uma história, uma teoria, uma enxurrada ( $1^{\mathrm{a}} \mathrm{Ed}$. ed.). (T. A. Calil, Trad.) São Paulo: Editora Companhia das Letras.

GLOBO NEWS,. (Acesso em: 25/03/2014). Informação é igual Comida - Globo News HD (2013). Fonte: Globo News: Disponível em: <http://www.youtube.com/watch?v=MJ80Gvg0qsY>

GLOBO NEWS,. (s.d.). Informação é como água - Globo News HD (2013). Fonte: GLOBO NEWS: 〈http://www.youtube.com/watch?v=ofdNa6G-e4w>

GOMES, L. F. (14 de maio de 2009). Definição de crime organizado e a Convenção de Palermo. Fonte: http://ww3.lfg.com.br/public_html/article.php?story=20090504104529281

INTERPOL. (2016). Cybercrime. Fonte: Interpol: http://www.interpol.int/Crimeareas/Cybercrime/Cybercrime

IRANLEI, A. C. (26 de Maio de 2014). O crime organizado transnacional e suas consequências socioeconômicas. Fonte: Juristas: http://www.juristas.com.br/informacao/artigos/o-crime-organizado-transnacional-e-suasconsequencias-socioeconomicas/1986/

KNIGNT, J. (2004). Terrorism, Domestic. Em K. LERNER, \& B. W. LERNER, Encyclopedia of espionage, intelligence, and security. United States of America: Gale. 
LORENZ, E. N. (1994.). In the wake of chaos: Unpredictable order in dynamical systems. Chicago: University of Chicago press.

LUFT, E. (2004). Terrorism, Philosophical and Ideological Origins. Em K. LERNER , \& B. W. LERNER, Encyclopedia of espionage, intelligence and secutity. Estados Unidos da América: Gale.

Ministério Público Federal. (23 de novembro de 2001). CONVENÇÃO SOBRE O CIBERCRIME. Fonte: MINISTÉRIO PÚBLICO FEDERAL: http://www.internacional.mpf.mp.br/normas-e-legislacao/legislacao/legislacoes-pertinentesdo-brasil/docs_legislacao/convencao_cibercrime.pdf

NORTON SYMANTEC. (24 de SETEMBRO de 2016). ( O que é crime cibernético? http://br.norton.com/cybercrime-definition). Fonte: NORTON NORTON SYMANTEC: http://br.norton.com/cybercrime-definition

OLIVEN, R. G. (2006). Fronteiras: arte e pensamento na época do multiculturalismo. Porto Alegre: Sulina.

ONU. (Setembro de 2013). Chefe da ONU diz que terrorismo está crescendo e pede mais esforços para combater essa ameaça. Fonte: ONUBR: http://www.onu.org.br/chefe-daonu-diz-que-terrorismo-esta-crescendo-e-pede-mais-esforcos-para-combater-essa-ameaca/

ONU. (outubro de 2013). Naçoes Unidas no Brasil. Fonte: Crime organizado transnacional gera 870 bilhões de dólares por ano, alerta campanha do UNODC.: https://nacoesunidas.org/convencao-da-onu-contra-crime-organizado-transnacionalcomemora-10-anos/

ONU. (2016). $13^{\circ}$ Congresso sobre o Crime da ONU: o impacto dos delitos no desenvolvimento. Acesso em 25/09/2016, disponível em UNITED NATION INFORMATION SERVICE:

http://www.unis.unvienna.org/unis/en/events/2015/crime_congress_cybercrime.html 
SAFERNET. (25 de SETEMBRO de 2016). Indicadores da Central Nacional de Denúncias de Crimes Cibernéticos. Fonte: safernet.org.br: http://indicadores.safernet.org.br/

SILVA, V. d. (2014). Inteligência criminal em prol da prevenção e repressão ao crime organizado no Brasil. Revista Jurídica do MPE-TO.

TAVARES, J. A. (2006). Forças Motrizes da Política no limiar do século XXI. Em F. SCHULER, \& M. d. BARCELLOS, Fronteiras: Arte e pensamento na época do multiculturalismo. Porto Alegre: Sulina.

TURING, A. M. (1950). "Computing Machinery and Intelligence”, Minds and Machines.

UNODC. (Agosto de 2016). Transnational Organized Crime. Fonte: Unodc: https://www.unodc.org/documents/toc/factsheets/TOC12_fs_general_EN_HIRES.pdf

UNODC, U. (Fevereiro de 2013). Comprehensive study on cybercrime. Fonte: Unodc: https://www.unodc.org/documents/commissions/CCPCJ/CCPCJ_Sessions/CCPCJ_22/_ECN15-2013-CRP05/Comprehensive_study_on_cybercrime.pdf

USA. (26 de Outubro de 2001). Public Law 107-56. Estados Unidos da América.

VASCONCELOS, C. E. (Março de 2014). Atos violentos vistos no Brasil não são terrorismo. Fonte: Conjur: http://www.conjur.com.br/2014-mar-17/carlos-vasconcelos-atosviolentos-vistos-brasil-nao-sao-terrorismo

VOITCH, G. (s.d.). “No Brasil, só 5\% dos homicídios são elucidados”. Acesso em <20/06/2014>, disponível em Jornal O Globo: <http://oglobo.globo.com/brasil/no-brasil-so-5dos-homicidios-sao-elucidados-7279090\#ixzz35iJiQPBj>

Weaver, W., \& Shannon, C. E. (1949). The Mathematical Theory of Communication. Illinois: Urbana: University of Illinois Press. 